\title{
Glycemic control after initiating basal insulin therapy in patients with type 2 diabetes: a primary care database analysis
}

This article was published in the following Dove Press journal:

Diabetes, Metabolic Syndrome and Obesity: Targets and Therapy

14 January 2015

Number of times this article has been viewed

\author{
Karel Kostev' \\ Franz W Dippel² \\ Wolfgang Rathmann ${ }^{3}$ \\ 'IMS Health, Frankfurt, ${ }^{2}$ Sanofi-Aventis \\ Deutschland $\mathrm{GmbH}$, Berlin, ${ }^{3}$ Institute \\ of Biometrics and Epidemiology, \\ German Diabetes Center, Düsseldorf, \\ Germany
}

Background: When target glycated hemoglobin $\left(\mathrm{HbA}_{1 \mathrm{c}}\right)$ levels are not reached, basal insulin therapy should be considered in type 2 diabetes. The objective of this report was to describe the predictors of glycemic control (strict criterion: $\mathrm{HbA}_{1 \mathrm{c}} \leq 6.5 \%$ ) during the first year after initiating basal insulin therapy in primary care.

Methods: The study applied a retrospective approach using a nationwide database in Germany (Disease Analyzer, IMS Health, January 2008 to December 2011, including 1,024 general and internal medicine practices). Potential predictors of glycemic control considered were age, sex, duration of diabetes, type of basal insulin, comedication with short-acting insulin, baseline $\mathrm{HbA}_{1 \mathrm{c}}$, previous oral antidiabetic drugs, diabetologist care, private health insurance, macrovascular and microvascular comorbidity, and concomitant medication. Multivariable logistic regression models were fitted with glycemic control as the dependent variable.

Results: A total of 4,062 type 2 diabetes patients started basal insulin (mean age 66 years, males $53 \%$, diabetes duration 4.8 years, mean $\mathrm{HbA}_{1 \mathrm{c}} 8.8 \%$ ), of whom 295 (7.2\%) achieved an $\mathrm{HbA}_{1 \mathrm{c}} \leq 6.5 \%$ during the one-year follow-up. Factors positively associated with $\mathrm{HbA}_{\mathrm{lc}} \leq 6.5 \%$ in logistic regression were male sex (odds ratio 1.59, 95\% confidence interval 1.23-2.04), insulin glargine (reference neutral protamine Hagedorn; odds ratio 1.43, 95\% confidence interval 1.09-1.88), short-acting insulin (odds ratio 1.33, 95\% confidence interval 1.01-1.76), and prior treatment with metformin, dipeptidyl peptidase-4 inhibitors, and diuretics. Lipid-lowering drugs were associated with a lower odds of reaching the glycemic target.

Conclusion: Few type 2 diabetes patients (7\%) reached the glycemic target $\left(\mathrm{HbA}_{1 \mathrm{c}} \leq 6.5 \%\right)$ after one year of basal insulin therapy. Achievement of the glycemic target was associated with type of basal insulin, additional short-acting insulins, previous antidiabetic medication, and other comedication, eg, diuretics or lipid-lowering drugs.

Keywords: insulin initiation, type 2 diabetes, glycemic control, basal insulin, primary care

\section{Introduction}

There are limited data on the effectiveness of real-life treatment of type 2 diabetes patients. ${ }^{1}$ Recently, glycemic control in type 2 diabetes patients insured by a large sickness fund (AOK PLUS, 2010-2011) was analyzed in Germany. ${ }^{1}$ Based on documentation from disease management programs, 59\% showed a glycated hemoglobin $\left(\mathrm{HbA}_{1 \mathrm{c}}\right)<7.0 \%, 36.5 \%$ had an $\mathrm{HbA}_{1 \mathrm{c}}$ of $7 \%-9 \%$, and an unacceptable level of $>9 \%$ was recorded in $4.5 \% .{ }^{1}$ Overall, a mean $\mathrm{HbA}_{1 \mathrm{c}}$ of $6.98 \%$ indicates good glycemic control. ${ }^{1}$ This observation is in line with a previous population-based study from Southern Germany. ${ }^{2}$ The mean $\mathrm{HbA}_{1 \mathrm{c}}$ was $7.2 \%$ in type 2 diabetes patients in the population, ${ }^{2}$ and increased with a longer diabetes duration in this cross-sectional survey. ${ }^{2}$ Longitudinal data from general practices in Germany also indicated that the $\mathrm{HbA}_{1 \mathrm{c}}$ deteriorates over
Correspondence: Karel Kostev IMS Health, Darmstädter Landstraße 108, 60598 Frankfurt am Main, Germany Tel +49696604 4878

Email kkostev@de.imshealth.com 
the course of type 2 diabetes. ${ }^{3}$ Beta-cell dysfunction and/or beta-cell loss is now recognized as a major factor in the progression of type 2 diabetes. The United Kingdom Prospective Diabetes Study showed that beta-cell function was already decreased by $50 \%$ at the time of the diagnosis and it continued to decline over the 6-year observation period, even with ongoing oral antidiabetic therapy. ${ }^{4}$

Once oral antidiabetic treatment has failed, starting basal supported oral therapy with either insulin glargine, insulin detemir, or neutral protamine Hagedorn (NPH) insulin is recommended in type 2 diabetes patients. ${ }^{5}$ Few studies have examined glycemic control $\left(\mathrm{HbA}_{1 \mathrm{c}}\right)$ in type 2 diabetes patients after initiation of basal insulin therapy in a realworld setting. ${ }^{6-10}$ The objective of the present study was to describe the predictors (clinical characteristics, medication) of glycemic control (strict criterion: $\mathrm{HbA}_{1 \mathrm{c}} \leq 6.5 \%$ ) during the first year after initiating basal insulin therapy in primary care practices.

\section{Materials and methods}

The study applied a retrospective approach using a nationwide database in Germany. The Disease Analyzer (IMS Health) assembles drug prescriptions, diagnoses, and basic medical and demographic data obtained from the practice computer system. ${ }^{11}$ The period analyzed was January 2008 to December 2011 (including 1,024 general and internal medicine practices). Patients with type 2 diabetes, who had basal insulin (glargine, detemir, NPH insulin) initiated, whichever came first (index date), were identified. The practice visit records were used to determine 12-month prior and 12-month post index continuous follow-up, respectively. Only patients with continuous basal insulin prescriptions were included.

The one-year outcome was reaching a strict $\mathrm{HbA}_{1 \mathrm{c}}$ target $\leq 6.5 \%$ according to German treatment guidelines. ${ }^{12}$ Potential predictors of glycemic control considered were age, sex, diabetes duration, type of basal insulin, comedication with short-acting insulin, baseline $\mathrm{HbA}_{1 \mathrm{c}}$, previous oral antidiabetic drugs, diabetologist care, private health insurance, macrovascular and microvascular comorbidity, and concomitant medication. If available, the recorded body mass index before index date was also considered.

Descriptive statistics were applied, and two-sided $t$-tests and Chi-square test were used, defining a $P$-value of $<0.05$ as being statistically significant. Univariable logistic regression models model and a final multivariable logistic regression model were fitted with glycemic control as the dependent variable (SAS version 9.3.; SAS Institute, Cary, NC, USA).

\section{Results}

In total, 4,062 patients with type 2 diabetes started a basal supported oral treatment in the practices (Table 1). The mean age was $66 \pm 11.9$ years, the mean diabetes duration was $4.8 \pm 3.5$ years, and there were slightly more males $(53 \%)$. About one fifth were under the care of a diabetologist.

Table I Characteristics of type 2 diabetes patients in general practices stratified by glycemic control after first year of initiating basal insulin therapy (Disease Analyzer, Germany)

\begin{tabular}{|c|c|c|c|c|c|}
\hline & All & $\mathrm{HbA}_{\mathrm{Ic}} \leq 6.5 \%^{\mathrm{a}}$ & $\mathrm{HbA}_{\mathrm{Ic}}>6.5 \%^{\mathrm{a}}$ & $\begin{array}{l}\text { Odds ratio }{ }^{\mathrm{b}}(95 \% \mathrm{Cl}) \text {, } \\
\text { univariable }\end{array}$ & $\begin{array}{l}\text { Odds ratiob }(95 \% \mathrm{Cl}) \text {, } \\
\text { multivariable }\end{array}$ \\
\hline$n$ & 4,062 & 295 & 3,767 & & - \\
\hline Male sex (\%) & 53.1 & $62.7 *$ & $52.3 *$ & $1.53(1.20-1.96)$ & $1.58(1.23-2.04)$ \\
\hline Age (years) & 65.9 (II.9) & $66.1(12.4)$ & $65.8(11.9)$ & $1.00(0.99-1.01)$ & $1.00(0.99,1.01)$ \\
\hline Diabetes duration (years) & $4.8(3.5)$ & $4.8(3.9)$ & $4.8(3.5)$ & $1.00(0.97-1.04)$ & $0.99(0.96,1.03)$ \\
\hline Diabetologist care (\%) & 20.5 & 15.9* & $20.9 *$ & $0.72(0.52-0.99)$ & $0.83(0.58-1.19)$ \\
\hline Private insurance (\%) & 4.7 & 6.1 & 4.6 & $1.36(0.82-2.42)$ & $1.22(0.73-2.04)$ \\
\hline $\mathrm{HbA}_{\mathrm{Ic}}(\%)$ (baseline) & $8.8(1.6)$ & $9.0(1.9)$ & $8.8(1.6)$ & $1.06(0.99-1.14)$ & $1.04(0.97,1.12)$ \\
\hline Glargine (\%) & 45.3 & $55.6 *$ & $44.5 *$ & $1.44(1.12-1.86)^{c}$ & $1.43(1.09-1.88)^{c}$ \\
\hline Detemir (\%) & 15.2 & $9.8^{*}$ & $15.6 *$ & $0.73(0.49-1.1 \mathrm{I})^{\mathrm{d}}$ & $0.73(0.48-1.12)^{d}$ \\
\hline NPH insulins (\%) & 39.5 & 34.6 & 39.9 & (Reference) & (Reference) \\
\hline Short-acting insulins (\%) & 43.7 & 44.4 & 43.6 & $\mathrm{I} .03(0.8 \mathrm{I}-\mid .3 \mathrm{I})$ & $1.33(1.01-1.76)$ \\
\hline Metformin (\%) & 56.3 & $63.4 *$ & $55.7 *$ & $1.38(1.08-1.76)$ & $1.50(1.16-1.95)$ \\
\hline Sulfonylureas (\%) ${ }^{\mathrm{e}}$ & 37.9 & 36.6 & 38.0 & $0.94(1.74-1.20)$ & $0.85(0.65-1.11)$ \\
\hline DPP-4 inhibitors ${ }^{\mathrm{e}}(\%)$ & 19.5 & $25.4 *$ & $19.1 *$ & $1.45(1.10-1.91)$ & $1.49(1.11-1.99)$ \\
\hline Lipid lowering drugs $\left.{ }^{\mathrm{e}} \%\right)^{\mathrm{b}}$ & 41.8 & 37.6 & 42.1 & $0.83(0.65-1.06)$ & $0.69(0.54-0.90)$ \\
\hline Diuretics $^{\mathrm{e}}(\%)$ & 34.4 & $43.4^{*}$ & $33.7^{*}$ & 1.51 (1.19-1.92) & $1.60(1.23-2.10)$ \\
\hline
\end{tabular}

Notes: Data are shown as the mean \pm standard deviation or proportion (\%), $* P<0.05$; alast recorded $\mathrm{HbA}$ during one year of follow-up after initiating basal insulin therapy; bodds ratios were computed using multivariable logistic regression (dependent variable: $\mathrm{HbA}_{\mathrm{lc}} \leq 6.5 \%$ versus $>6.5 \%$ ) including all variables in the table and further adjusting for macrovascular (coronary heart disease, myocardial infarction, stroke) and microvascular (retinopathy, nephropathy, neuropathy) complications (data not shown, all complications not significantly associated with glycemic control had $\mathrm{P}>0.05$ ); ' glargine versus $\mathrm{NPH}$; detemir versus $\mathrm{NPH}$; ' at least one prescription before initiating basal insulin. Abbreviations: $\mathrm{Cl}$, confidence interval; DPP-4, dipeptidyl peptidase; NPH, neutral protamine Hagedorn; HbA ${ }_{1 \mathrm{c}}$, glycated hemoglobin. 
More than half were previously treated with metformin (sulfonylureas 37.9\%) and about 20\% had received prior dipeptidyl peptidase (DPP)-4 inhibitor prescriptions. Only $2.8 \%$ had received glucagon-like peptide- 1 analogs.

Glargine was the most frequently prescribed basal insulin, followed by NPH and detemir (Table 1). Mean $\mathrm{HbA}_{1 \mathrm{c}}$ was $8.8 \%$ at baseline and declined by $-0.8 \%$ units over the year. Overall, 295 (7.2\%) patients achieved an $\mathrm{HbA}_{1 \mathrm{c}} \leq 6.5 \%$ during the one-year follow-up $(20.9 \%$ achieved a target of $<7 \%$ ). About $44 \%$ were additionally treated with shortacting insulins (glargine 29.3\%, detemir 47.2\%, NPH 58.9\%; glargine versus NPH $P<0.0001$; detemir versus NPH $P<0.05)$.

There were significant differences between patients who did and did not reach the glycemic target during one-year follow-up (Table 1). Whereas no differences were found for age and diabetes duration, the group with $\mathrm{HbA}_{1 \mathrm{c}} \leq 6.5 \%$ contained more males and was less often under specialized diabetes care. They were treated more often with insulin glargine and with metformin and DPP-4 inhibitor than those with higher $\mathrm{HbA}_{1 \mathrm{c}}$ levels during follow-up. Finally, diuretics were prescribed more often in patients with more favorable glycemic control.

Factors positively associated with $\mathrm{HbA}_{1 \mathrm{c}} \leq 6.5 \%$ at follow-up in multivariable logistic regression were male sex (odds ratio [OR] 1.59, 95\% confidence interval [CI] 1.23-2.04), insulin glargine (reference NPH; OR 1.43, 95\% CI 1.09-1.88), short-acting insulin (OR 1.33; 95\% CI 1.01-1.76), and prior treatment with metformin, DPP-4 inhibitors, and diuretics (Table 1). Baseline treatment with lipid-lowering drugs was associated with a lower odds of reaching the glycemic target.

No significant relationships were observed for age, diabetes duration, diabetologist care, private health insurance, insulin detemir, baseline $\mathrm{HbA}_{1 \mathrm{c}}$, and macrovascular and microvascular complications (data not shown). A subgroup analyses including 1,246 patients with recorded body mass index at baseline yielded largely similar results (data not shown), eg, use of insulin glargine (reference NPH) was significantly related to the $\mathrm{HbA}_{1 \mathrm{c}}$ target (OR 1.76, 95\% CI 1.05-2.95).

\section{Discussion}

The aim of the present study was to examine the proportion and predictors of a strict glycemic control $\left(\mathrm{HbA}_{1 \mathrm{c}} \leq 6.5 \%\right)$ in patients with type 2 diabetes who initiated a basal supported oral treatment. Only few patients $(7 \%)$ reached this strict glycemic target after one year and $21 \%$ achieved a more moderate level $\left(\mathrm{HbA}_{1 \mathrm{c}}<7 \%\right)$.
First, the type of basal insulin (insulin glargine) was related to successfully achieving the target. Even though prescription of short-acting insulin (basal-bolus therapy) was lowest in combination with insulin glargine (29.3\%), the proportion of responders reaching the $\mathrm{HbA}_{1 \mathrm{c}}$ target was highest (55.6\%). In contrast with randomized controlled trials, ${ }^{13-16}$ previous real-world studies of glycemic outcomes on basal insulins yielded inconsistent results. ${ }^{6-10}$

A retrospective database study from the USA showed a larger $\mathrm{HbA}_{1 \mathrm{c}}$ change $(-1.11 \%$ versus $-0.96 \%, P=0.048)$ during one-year follow-up in users of insulin glargine than in users of insulin detemir, ${ }^{6}$ whereas two other US studies found no significant differences in $\mathrm{HbA}_{1 \mathrm{c}}$ outcomes between the two insulins. ${ }^{7,8}$ In the Swedish National Diabetes Register, the one-year change in $\mathrm{HbA}_{1 \mathrm{c}}$ also did not differ between glargine and detemir when compared with NPH insulin. ${ }^{9}$ Unfortunately, these results are difficult to compare with each other because of the different study populations and study designs.

Second, the addition of short-acting insulin increased the odds of achieving the $\mathrm{HbA}_{1 \mathrm{c}}$ target. In line with this observation, addition of glulisine, a rapid-acting insulin analog, showed a substantial improvement in $\mathrm{HbA}_{1 \mathrm{c}}$ levels in patients who were insufficiently controlled with insulin glargine and oral antidiabetic agents. ${ }^{16}$

Interestingly, male sex was a predictor of having an $\mathrm{HbA}_{1 \mathrm{c}}$ $<6.5 \%$. Similarly, male patients in Swedish primary care centers showed slightly more favorable glycemic control than females $\left(\mathrm{HbA}_{1 \mathrm{c}}<6.5 \%\right.$, 59\% versus 54\%, respectively). ${ }^{17}$ Further, prior treatment with certain antidiabetic drugs (metformin, DPP-4 inhibitors) was associated with an increased odds of achieving the glycemic target. The combination of metformin with insulin has been previously shown to improve glycemic control. ${ }^{18}$ DPP-4 inhibitors have also been reported to improve $\mathrm{HbA}_{1 \mathrm{c}}$ in basal insulin therapy without the risk of hypoglycemia. ${ }^{19}$ Finally, previous use of diuretics (favorable) and lipid-lowering agents (unfavorable) were predictors of the glycemic outcome.

Our study indicates that despite the publication of international and national guidelines, adequate control of insulin-treated patients with type 2 diabetes remains beset with challenges. ${ }^{5,12}$ Although we found some factors that were related to better glycemic control, future clinical studies should elucidate the underlying pathophysiological mechanisms (eg, insulin sensitivity, beta-cell function). ${ }^{4}$

Several limitations of the present study should be mentioned. First, no valid information on prescribed daily doses and important outcome measures (eg, hypoglycemia) 
were available. Further, assessment of diabetes duration and comorbidity relied on ICD-10 (International Classification of Diseases, Tenth Revision) codes by primary care physicians only. Finally, body mass index values were only available for a subgroup.

In conclusion, this real-world study shows that achievement of the glycemic target $\left(\mathrm{HbA}_{1 \mathrm{c}} \leq 6.5 \%\right)$ among patients with type 2 diabetes initiating basal insulin is associated with the type of basal insulin, additional short-acting insulins, previous antidiabetic medication, and other comedication, including diuretics and lipid-lowering drugs.

\section{Disclosure}

The study was supported by an unrestricted grant from Sanofi-Aventis. The authors report no other conflicts of interest in this work.

\section{References}

1. Wilke T, Groth A, Fuchs A, et al. Real life treatment of diabetes mellitus type 2 patients: an analysis based on a large sample of 394,828 German patients. Diabetes Res Clin Pract. 2014;106(2):275-285.

2. Icks A, Rathmann W, Haastert B, et al. [Quality of care and extent of complications in a population-based sample of patients with type 2 diabetes mellitus. The KORA Survey 2000]. Dtsch Med Wochenschr. 2006;131:73-88. German.

3. Ott P, Benke I, Stelzer J, Köhler C, Hanefeld M. [Diabetes in Germany (DIG) study. A prospective 4-year-follow-up study on the quality of treatment for type 2 diabetes in daily practice]. Dtsch Med Wochenschr. 2009;134:291-297. German.

4. Wright A, Burden AC, Paisey RB, Cull CA, Holman RR; UK Prospective Diabetes Study Group. Sulfonylurea inadequacy: efficacy of addition of insulin over 6 years in patients with type 2 diabetes in the UK Prospective Diabetes Study (UKPDS 57). Diabetes Care. 2002;25:330-336.

5. Inzucchi SE, Bergenstal RM, Buse JB, et al. Management of hyperglycaemia in type 2 diabetes: a patient-centered approach. Position statement of the American Diabetes Association (ADA) and the European Association for the Study of Diabetes (EASD). Diabetologia. 2012;55:1577-1596.

6. Davis KL, Tangirala M, Meyers JL, Wei W. Real-world comparative outcomes of US type 2 diabetes patients initiating analog basal insulin therapy. Curr Med Res Opin. 2013;29:1083-1091.

7. McAdam-Marx C, Bouchard J, Aagren M, Nelson R, Brixner D. Analysis of glycaemic control and weight change in patients initiated with human or analog insulin in an US ambulatory care setting. Diabetes Obes Metab. 2010;12:54-64
8. Borah BJ, Darkow T, Bouchard J, Aagren M, Forma F, Alemayehu B. A comparison of insulin use, glycemic control, and health care costs with insulin detemir and insulin glargine in insulin-naive patients with type 2 diabetes. Clin Ther. 2009;31:623-631.

9. Eliasson B, Ekström N, Bruce Wirta S, Odén A, Fard MP, Svensson AM. Metabolic effects of basal or premixed insulin treatment in 5077 insulinnaïve type 2 diabetes patients: registry-based observational study in clinical practice. Diabetes Ther. 2014;5:243-254.

10. Freemantle N, Balkau B, Home PD. A propensity score matched comparison of different insulin regimens 1 year after beginning insulin in people with type 2 diabetes. Diabetes Obes Metab. 2013;15: $1120-1127$.

11. Becher H, Kostev K, Schröder-Bernhardi D. Validity and representativeness of the Disease Analyzer patient database for use in pharmacoepidemiological and pharmacoeconomic studies. Int J Clin Pharmacol Ther. 2009;47:617-626.

12. Matthaei S, Bierwirth R, Fritsche A, et al; German Diabetes Association. Medical antihyperglycaemic treatment of type 2 diabetes mellitus: update of the evidence-based guideline of the German Diabetes Association. Exp Clin Endocrinol Diabetes. 2009;117:522-557.

13. Swinnen SG, Dain MP, Aronson R, et al. A 24-week, randomized, treat-to-target trial comparing initiation of insulin glargine oncedaily with insulin detemir twice-daily in patients with type 2 diabetes inadequately controlled on oral glucose-lowering drugs. Diabetes Care. 2010;33:1176-1178.

14. Hollander P, Cooper J, Bregnhøj J, Pedersen CB. A 52-week, multinational, open-label, parallel-group, noninferiority, treat-to-target trial comparing insulin detemir with insulin glargine in a basal-bolus regimen with mealtime insulin aspart in patients with type 2 diabetes. Clin Ther. 2008;30:1976-1987.

15. Rosenstock J, Davies M, Home PD, Larsen J, Koenen C, Schernthaner G. A randomised, 52-week, treat-to-target trial comparing insulin detemir with insulin glargine when administered as add-on to glucose-lowering drugs in insulin-naïve people with type 2 diabetes. Diabetologia. 2008;51:408-416.

16. Lankisch MR, Ferlinz KC, Leahy JL, Scherbaum WA; Orals Plus Apidra and Lantus (OPAL) Study Group. Introducing a simplified approach to insulin therapy in type 2 diabetes: a comparison of two single-dose regimens of insulin glulisine plus insulin glargine and oral antidiabetic drugs. Diabetes Obes Metab. 2008;10:1178-1185.

17. Nilsson PM, Theobald H, Journath G, Fritz T. Gender differences in risk factor control and treatment profile in diabetes: a study in 229 Swedish primary health care centres. Scand J Prim Health Care. 2004;22: 27-31.

18. Kooy A, de Jager J, Lehert P, et al. Long-term effects of metformin on metabolism and microvascular and macrovascular disease in patients with type 2 diabetes mellitus. Arch Intern Med. 2009;169:616-625.

19. Drucker DJ, Nauck MA. The incretin system: glucagon-like peptide-1 receptor agonists and dipeptidyl peptidase- 4 inhibitors in type 2 diabetes. Lancet. 2006;368:1696-1705.

\section{Publish your work in this journal}

Diabetes, Metabolic Syndrome and Obesity: Targets and Therapy is an international, peer-reviewed open-access journal committed to the rapid publication of the latest laboratory and clinical findings in the fields of diabetes, metabolic syndrome and obesity research. Original research, review, case reports, hypothesis formation, expert opinion and commentaries are all considered for publication. The manuscript management system is completely online and includes a very quick and fair peer-review system, which is all easy to use. Visit http://www.dovepress.com/testimonials.php to read real quotes from published authors. 